\title{
Supplementary Material of
}

\section{Optical properties and oxidative potential of aqueous-phase products}

\section{from $\mathrm{OH}$ and ${ }^{3} \mathrm{C}^{*}$-initiated photolysis of eugenol}

Xudong $\mathrm{Li}^{\mathrm{a}}$, Ye Tao ${ }^{\mathrm{a}}$, Longwei Zhu ${ }^{\mathrm{a}}$, Shuaishuai $\mathrm{Ma}^{\mathrm{a}}$, Shipeng Luo ${ }^{\mathrm{a}}$, Zhuzi Zhao, Ning Sun ${ }^{\mathrm{a}}$, Zhaolian Ye $\mathrm{e}^{\mathrm{a},}$, Xinlei Ge $\mathrm{e}^{\mathrm{b},}$

${ }^{a}$ College of Chemistry and Environmental Engineering, Jiangsu University of Technology, Changzhou 213001, China

bJiangsu Key Laboratory of Atmospheric Environment Monitoring and Pollution Control, Collaborative Innovation Center of Atmospheric Environment and Equipment Technology, School of Environmental Sciences and Engineering, Nanjing University of Information Science and Technology, Nanjing 210044, China

*Corresponding author, Email: bess_ye@jsut.edu.cn; Tel: +86-519-86953266;

caxinra@163.com; Tel.: +86-25-58731394 


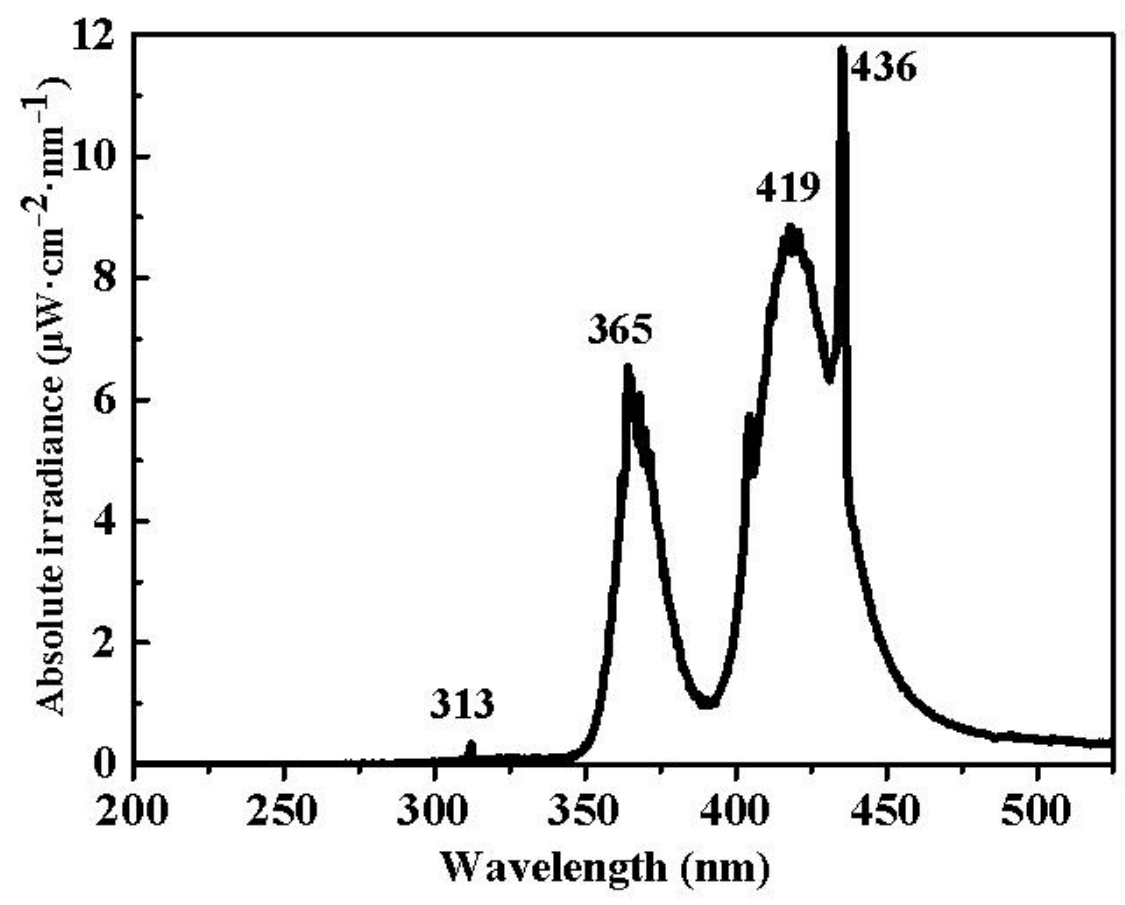

Figure S1. Irradiation intensity of simulated sunlight in this study
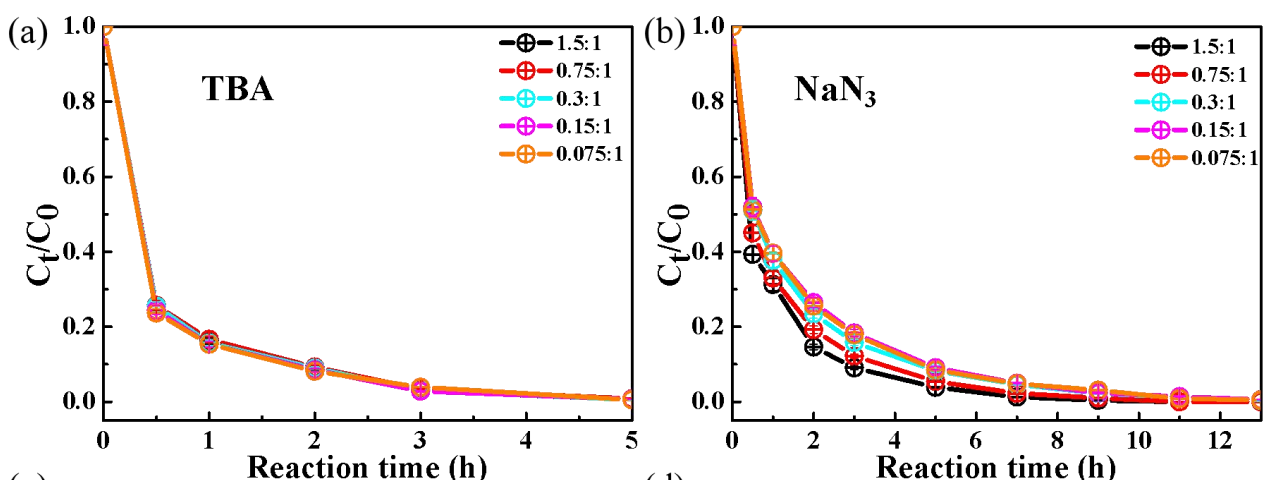

(c)
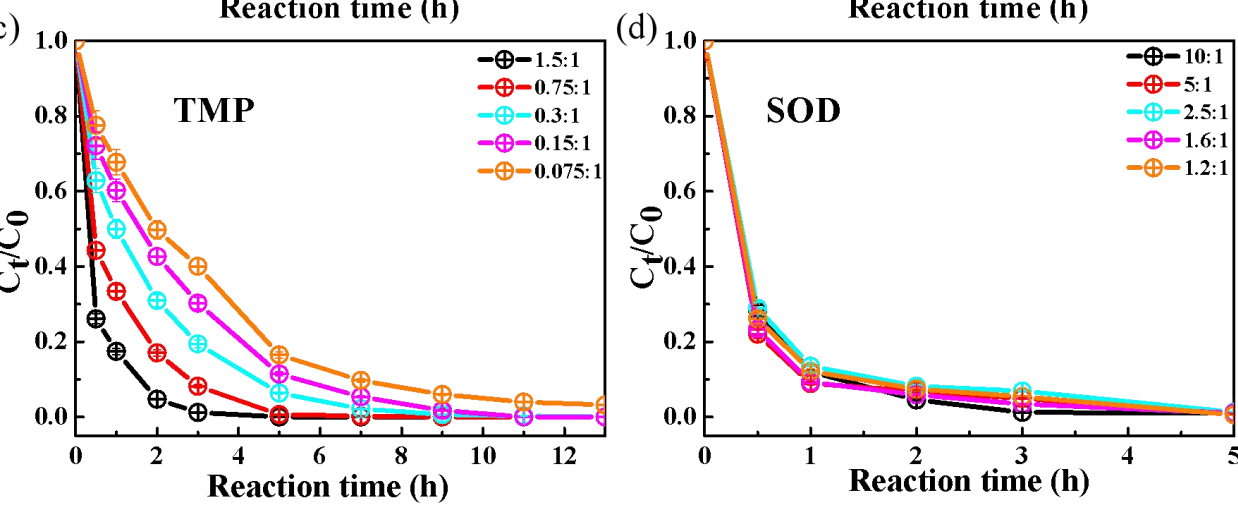

Figure S2. Ratio of residue concentration to initial concentration $\left(\mathrm{C}_{t} / \mathrm{C}_{0}\right)$ at different mole ratios as a function of reaction time with (a) TBA quencher, (b) $\mathrm{NaN}_{3}$ quencher, (c) TMP quencher and (d) SOD quencher. Legend represented mole ratios of eugenol to quenchers. 

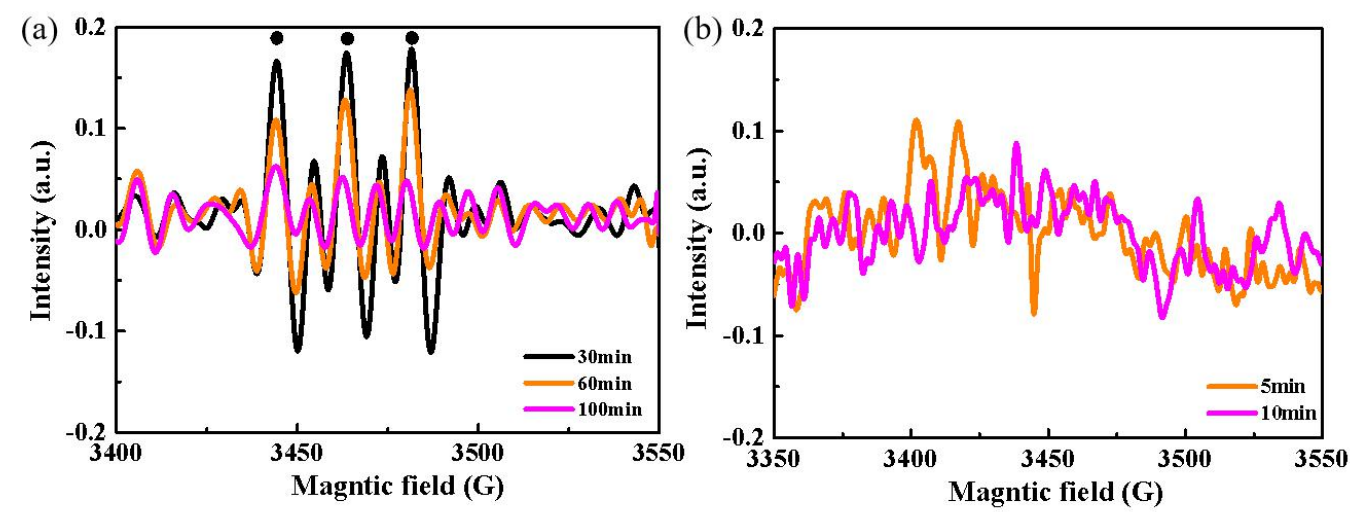

Figure S3. EPR spectra using (a) TEMP as a ${ }^{1} \mathrm{O}_{2}$ trapping agent in the ${ }^{3} \mathrm{C}^{*}$ oxidation and (b) $\mathrm{DMPO}$ as $\bullet \mathrm{OH}$ trapping agent in the $\mathrm{OH}$ oxidation.
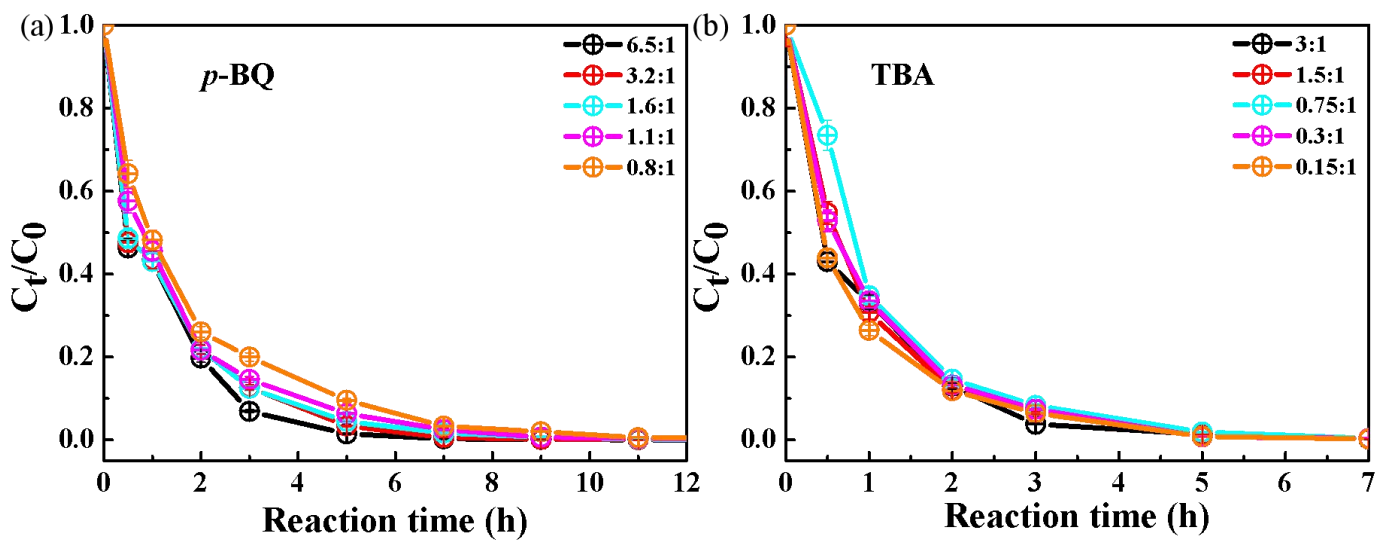

Figure S4. Ratio of residue concentration to initial concentration $\left(\mathrm{C}_{t} / \mathrm{C}_{0}\right)$ as a function of reaction time with (a) $p$-BQ quencher and (b) TBA quencher
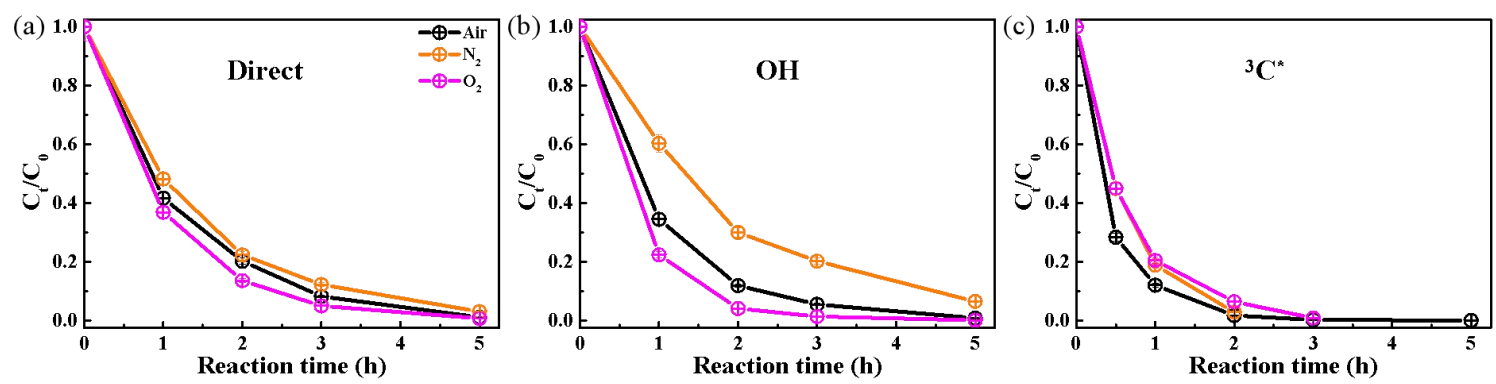

Figure S5. Ratio of remaining concentration to initial concentration $\left(C_{t} / C_{0}\right)$ as a function of reaction time at different saturated gases under (a) direct photolysis (b) OH-initiated and (c) ${ }^{3} \mathrm{C}^{*}$-initiated oxidation. 
(a)

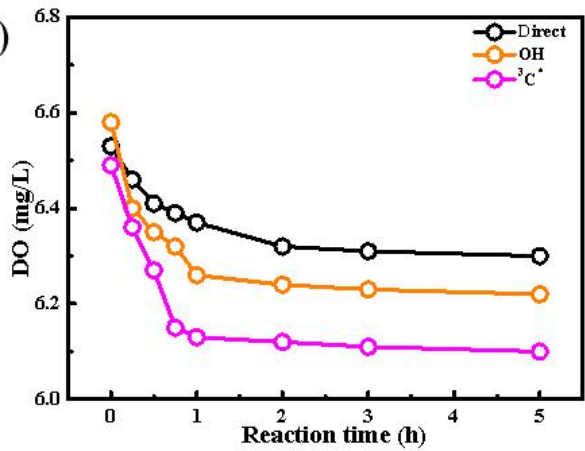

(c)

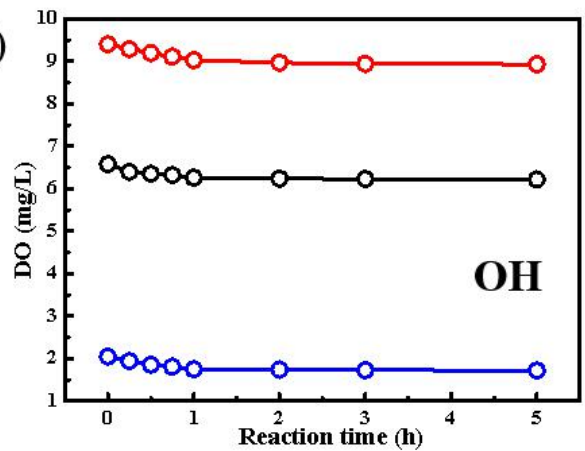

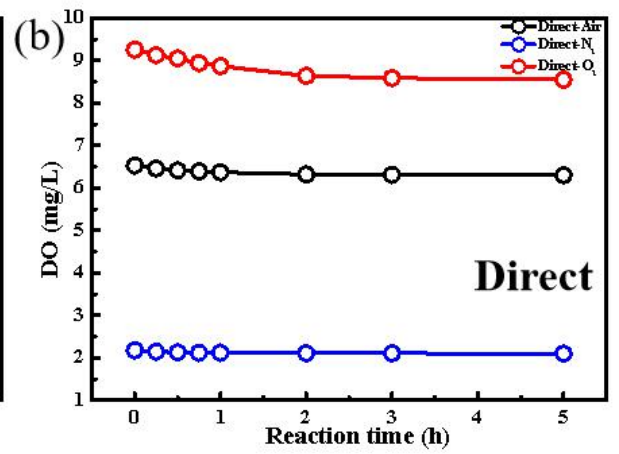

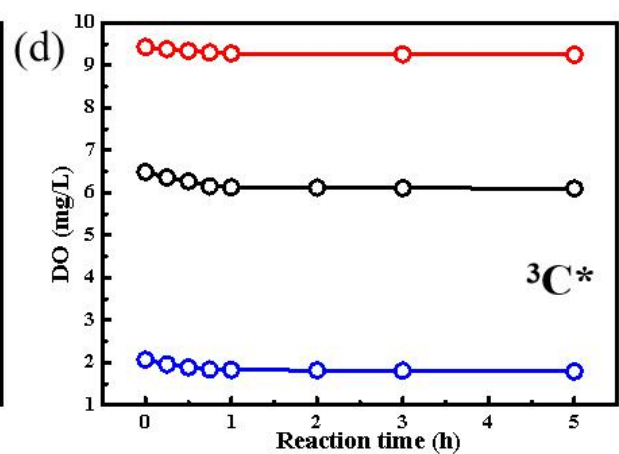

Figure S6. DO concentrations as a function of reaction time for (a) the three systems, and different saturated gases in the (b) Direct (c) $\mathrm{OH}(\mathrm{d}){ }^{3} \mathrm{C}^{*}$ system.

(a)

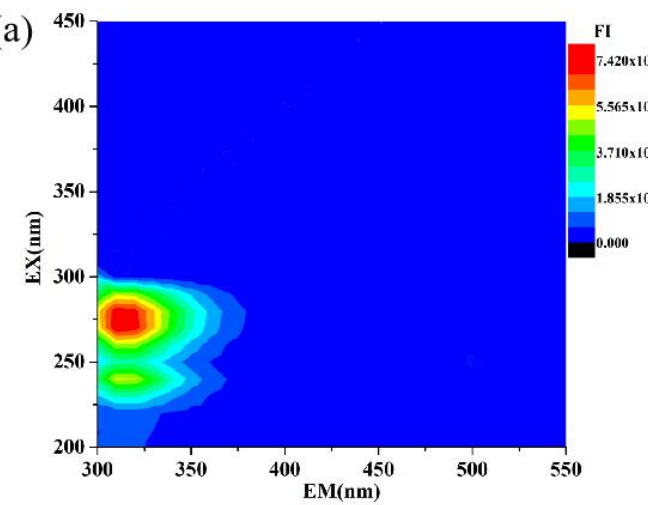

(c)

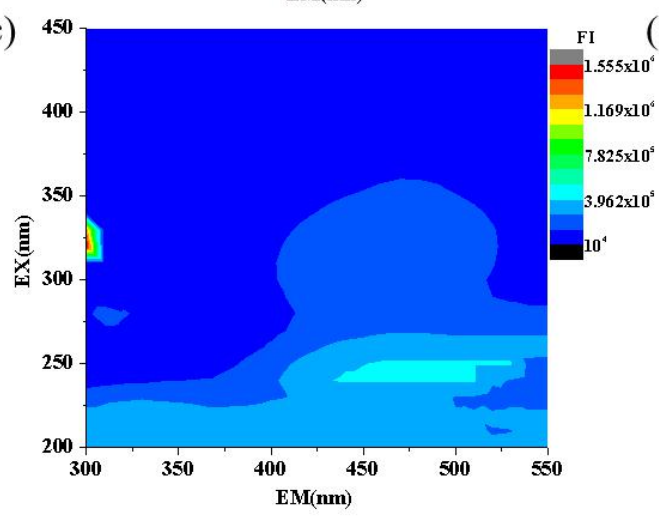

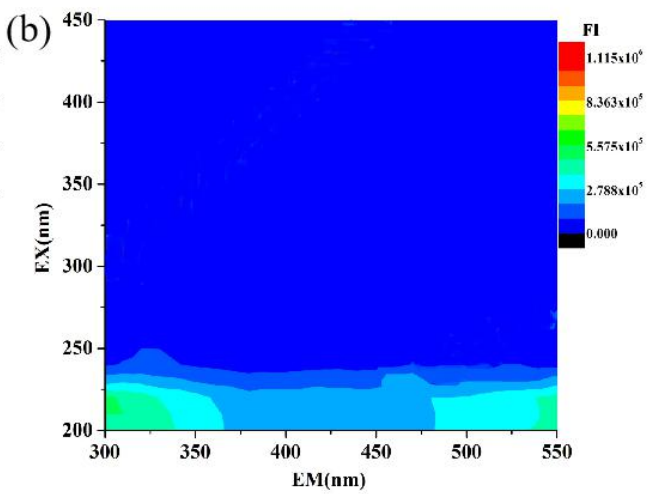

(d)

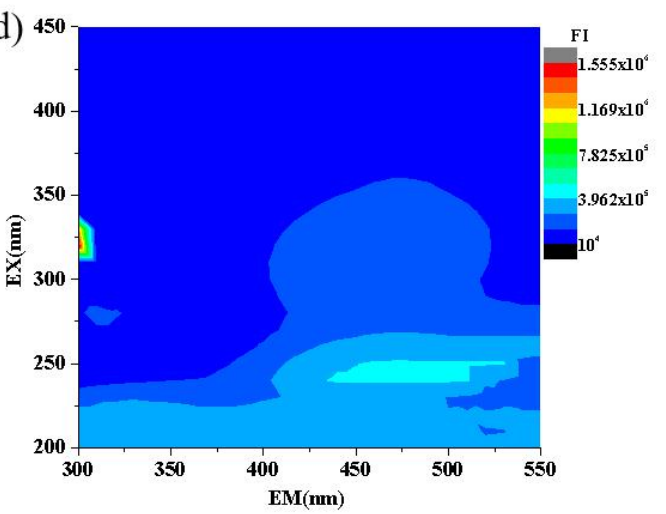

Figure S7. EEM spectra of (a) pure eugenol, (b) pure DMB $\left({ }^{3} \mathrm{C}^{*}\right.$ precursor), (c) solution at the end 
of reaction $(23 \mathrm{~h})$ in direct photolysis, and (d) in $\mathrm{OH}$ oxidation.

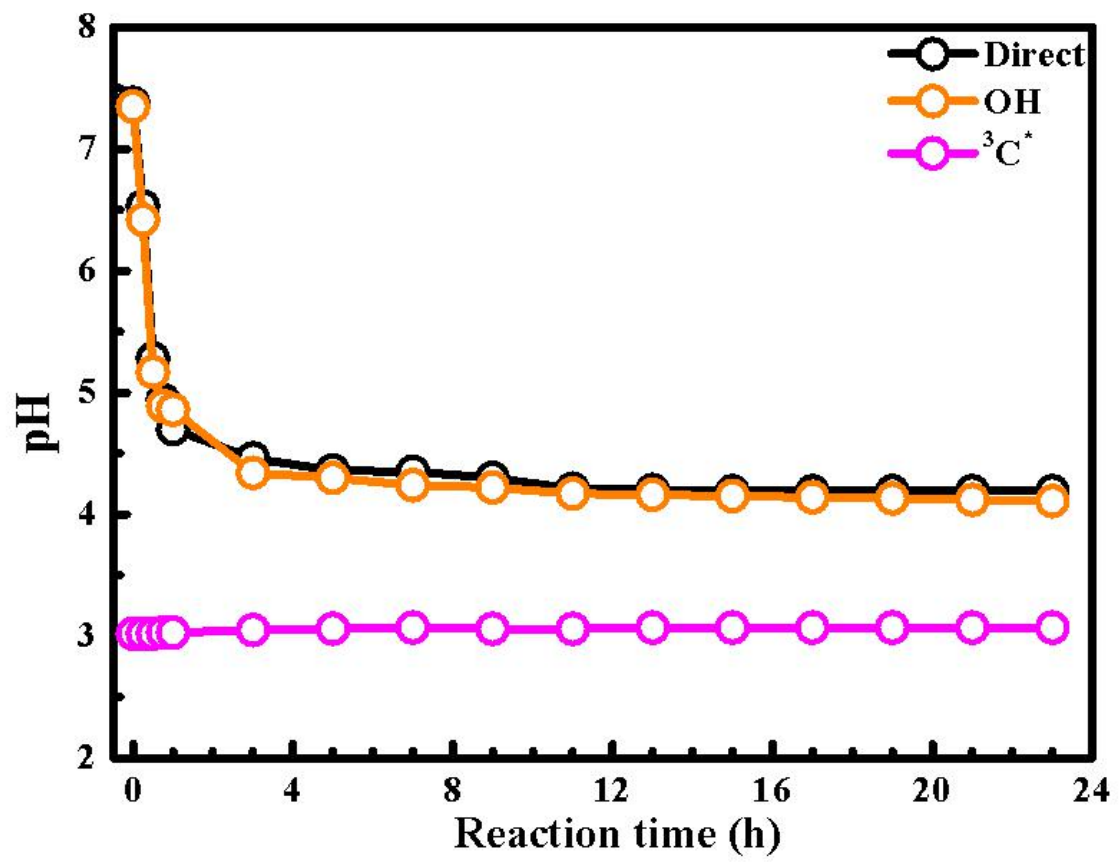

Figure S8. $\mathrm{pH}$ values as a function of reaction time for the three systems.

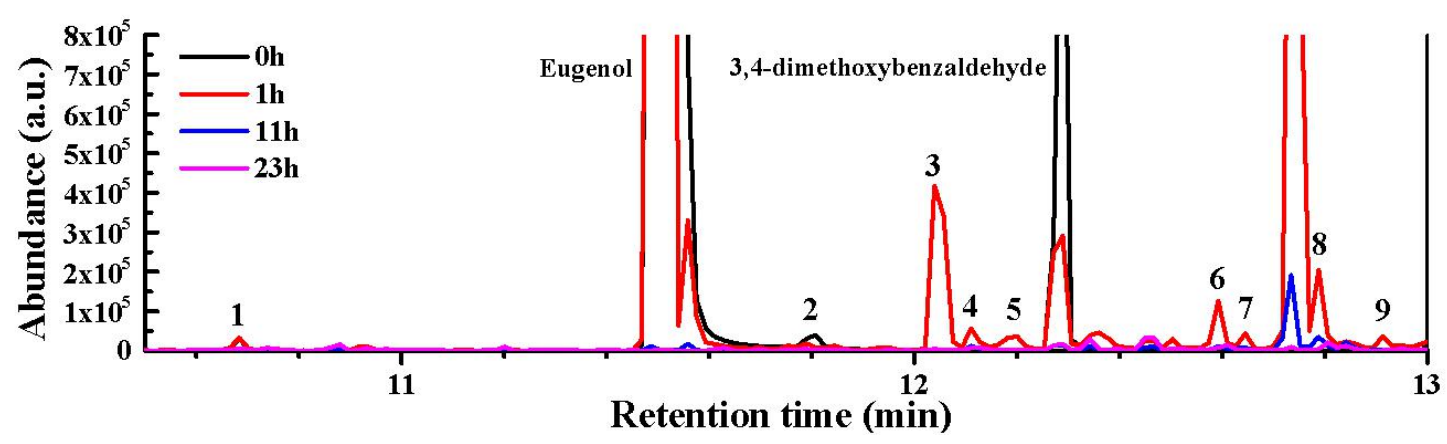

Figure S9. The total ion chromatograph (TIC) of GC-MS of extracted products under ${ }^{3} \mathrm{C}^{*}$ oxidation before and after photolysis of 1,11 , and $23 \mathrm{~h}$, respectively. 